\title{
Adsorption and determination of polycyclic aromatic hydrocarbons in water through the aggregation of graphene oxide
}

https://doi.org/10.1515/chem-2018-0078

received February 10, 2018; accepted May 29, 2018.

Abstract: In this study, a simple method was developed for the aggregation of graphene oxide (GO) with the addition of $\mathrm{NaCl}$ to concentrate and separate polycyclic aromatic hydrocarbons (PAHs) from water samples, and this method was used as a environmentally friendly method for the determination of PAHs. We demonstrate the uniform dispersion of GO sheets in aqueous samples for the fast high-efficiency adsorption of PAHs. Aggregation occurred immediately upon elimination of electrostatic repulsion by adding $\mathrm{NaCl}$ to neutralize the excessive negative charges on the surfaces of the GO sheets. The aggregates of GO and PAHs were separated and treated with hexane to form a slurry. The slurry was filtered and subjected to gas chromatography-mass spectroscopy (GC-MS) analysis. Based on a $40-\mathrm{mL}$ sample volume, limits of detection of 10-30 ng L ${ }^{-1}$ were obtained for 16 PAHs, with correlation coefficients $\left(\mathrm{R}^{2}\right)$ exceeding 0.99 . The method yielded good recovery, ranging from 80 to $111 \%$ and 80 to $107 \%$ for real spiked water samples at 100 and $500 \mathrm{ng} \mathrm{L}^{-1}$, respectively. Compared to traditional solid-phase extraction and liquid-liquid extraction methods, this method is free of organic reagents in the pretreatment procedure and uses only $1 \mathrm{~mL}$ hexane for sample introduction.

\footnotetext{
*Corresponding author: Bingjun Han, Analysis \& Testing Center, Chinese Academy of Tropical Agricultural Sciences, Hainan Provincial Key Laboratory of Quality and Safety for Tropical Fruits and Vegetables, Haikou, Hainan 571101, China, E-mail: hanbjun@163.com Ya Li, Bing Qian, Yan He, Lixu Peng: Analysis \& Testing Center, Chinese Academy of Tropical Agricultural Sciences, Hainan Provincial Key Laboratory of Quality and Safety for Tropical Fruits and Vegetables, Haikou, Hainan 571101, China

Bing Qian, Lixu Peng: Environment and Plant Protection Institute, Chinese Academy of Tropical Agricultural Sciences, Haikou, Hainan 571101, China

Bing Qian, Huamei Yu: College of Environment and Plant Protection, Hainan University, Haikou, Hainan 570228, China
}

Keywords: graphene oxide; aggregation; polycyclic aromatic hydrocarbons.

\section{Introduction}

Environmentally friendly (green) analytical methodologies are in high demand to reduce the risks of chemical use to humans and the environment [1]. However, the traditional analytical methods used to detect environmental pollutants often contribute to further pollution through the chemicals used in analysis, as hazardous chemicals are required for analytical sample preparation, quality control, and calibration $[2,3]$. Sometimes these chemicals are more toxic than the original analyzed sample. Therefore, the development of novel green analytical methods remains necessary.

Polycyclic aromatic hydrocarbons (PAHs) are a class of common and persistent environmental pollutants containing three or more benzene rings, and they are toxic to aquatic animals and humans [4]. PAHs are frequently found in the soil, air and water, where they can negatively impact human health [5]. Therefore, the rapid and sensitive determination of $\mathrm{PAH}$ compounds in environmental samples is urgently needed [6-9]. However, the traditional liquid-liquid [10] and solid-phase (SPE) [11,12] methods for extraction before determination of PAHs usually consume large quantities of solvents, which lead to further polluting of the environment [13-16].

Graphene oxide (GO) is a two-dimensional carbon nanomaterial that has attracted significant scientific attention in recent years [17-19]. GO can be obtained by the strong oxidation of graphite; it possesses a layered structure and negatively charged surfaces [20]. At the edges of the carbon layers, dense carboxyl groups significantly affect the van der Waals interactions among adjacent graphene layers and render the material strongly hydrophilic [21,22]. Thus, many hydrophilic and polar substances including pigments [23,24], endogenous estrogen [25], heavy metal ions [26,27], phenols [28], and 
basic species[29] can be adsorbed onto the GO surface through hydrogen bonding, anion- $\pi$, and electrostatic interactions [30,31].

GO has been reported to adsorb PAH compounds with high efficiency [31]. However, the complete removal of small GO sheets from a well-dispersed solution is difficult. The traditional separation methods of highspeed centrifugation and filtering through $0.22-\mu \mathrm{m}$ porous membrane filters are usually relatively cumbersome, time-consuming, and inefficient, and they typically result in incomplete separation. When GO is used to adsorb target compounds, the separation of GO from the solution remains slow and difficult. Fortunately, GO can form stable aqueous colloids that aggregate by changing the $\mathrm{pH}[32,33]$ or adding electrolyte solutions [34,35]. Based on this theory, GO was successfully used to extract and separate trace toxic metals including $\mathrm{Pb}, \mathrm{Cd}, \mathrm{Bi}$, and $\mathrm{Sb}$ [36].

Recently, carbon nanomaterials were also applied successfully to the extraction and separation of organic compounds through SPE. For example, graphene has been used as a sorbent for the isolation of propyl gallate and butylated hydroxyanisole from complex food sample matrices [37]. Magnetic SPE based $\mathrm{Fe}_{3} \mathrm{O}_{4} @ G O$ nanocomposite was also used to extract ethyl vanillin, trans-cinnamic acid, methyl cinnamate, ethyl cinnamate, and benzyl cinnamate from food samples [38]. However, carbon nanomaterial packed in a SPE cartridge usually becomes increasingly more compact during elution due to an aggregation phenomenon, which decreases extraction and purification efficiency over time. Moreover, large amounts of organic solvent are consumed in the elution of SPE column. Therefore, the aggregation of GO by adding electrolytes in liquid samples was applied to potentially improve the efficiency of the nanomaterial and to reduce the consumption of organic solvents.

The aim of this work was to investigate the impact of the aggregation of $\mathrm{GO}$ by introducing $\mathrm{NaCl}$ as an electrolyte solute during the extraction of PAHs from water. The isolated $\mathrm{GO}$-adsorbed $\mathrm{PAH}$ aggregates were transferred to a GC-MS detection system using a hexane solution for the introduction of a liquid sample. By exploiting the superior properties of GO, the proposed method showed excellent extraction efficiency and minimal organic solvent consumption compared to those in traditional methods.

\section{Experimental Section}

\subsection{Materials and Reagents}

All chemicals used in this work were of at least analytical grade. All solutions were prepared using $18 \mathrm{M} \Omega \cdot \mathrm{cm}$ deionized water (DIW) produced by a water-purification system (Millipore, USA). Commercial GO (thickness 0.55$1.2 \mathrm{~nm}$, purity > $95 \mathrm{wt} \%$; size $0.5-3 \mu \mathrm{m}$ ) was obtained from Chengdu Organic Chemicals Co., Ltd. (Chengdu, China). The GO solution of $1.0 \mathrm{mg} \mathrm{mL}{ }^{-1}$ prepared with DIW was used directly for the extraction. The liquid PAH standards (1000 $\mathrm{mg} \mathrm{L}^{-1}$ ) dissolved in methanol were purchased from the Agro-Environment Protection Institute (Tianjin, China). The selected PAHs were defined and nominated as priority pollutants by the United States Environmental Protection Agency (EPA), including naphthalene (NAP), acenaphthylene (ANY), acenaphthene (ANA), fluorene (FLU), phenanthrene (PHE), anthracene (ANT), fluoranthene (FLT), pyrene (PYR), benzo(a)anthracene (BaA), chrysene (CHR), benzo(b) fluoranthene $(\mathrm{BbF})$, benzo(k)fluoranthene $(\mathrm{BkF})$, benzo(a) pyrene (BaP), indeno(1,2,3-cd)pyrene (IPY), dibenzo(a,h) anthracene (DBA), and benzo(g,h,i)perylene (BPE). A stock solution of each compound with the concentration of 10 $\mathrm{mg} \mathrm{L}^{-1}$ was prepared in acetone and stored in amber screwcapped glass vials in the dark at $-20^{\circ} \mathrm{C}$. Working solutions were prepared daily by the appropriate dilution of the stock solutions with hexane before use. $\mathrm{NaCl}$ and other reagents were purchased from Guangzhou Chemical Reagent Factory (Guangzhou, China).

\subsection{Extraction Procedure}

A total of 15 water samples were used to evaluate the accuracy of the proposed method. Five river, five lake and five sea water samples were collected from Nandu River, Hongcheng Lake and Holiday Beach of Haikou, Hainan province of China. The samples were collected in precleaned quartz bottles and directly transported to the laboratory for immediate study after filtration with $0.22-\mu \mathrm{m}$ membrane filters. A $40-\mathrm{mL}$ portion of each water sample was accurately weighed and placed directly in a 50-mL precleaned Teflon centrifuge tube. After that, $4.0 \mathrm{~mL}$ of a high concentration $\left(1 \mathrm{mg} \mathrm{mL}^{-1}\right)$ of the $\mathrm{GO}$ dispersion was added to the tubes, which were allowed to mix for $5 \mathrm{~min}$ to achieve the complete adsorption of the analyte PAHs. When $\mathrm{NaCl}$ was added and mixed with the GO in the sample solution, GO aggregated quickly and was gradually deposited on the bottom of the tubes. Complete 
Table 1: Analytical performances of the developed method.

\begin{tabular}{|c|c|c|c|c|c|c|}
\hline PAHs & Retention time (min) & Selected ions & Regression equation & $r^{2}$ & Liner range $\left(\mathrm{ng} \mathrm{L}^{-1}\right)$ & LODs $\left(\mathrm{ng} \mathrm{L}^{-1}\right)$ \\
\hline NAP & 6.05 & $128^{a}, 129,127$ & $Y=0.982 x+0.003$ & 0.996 & $50-2000$ & 10 \\
\hline ANY & 9.29 & $152^{\mathrm{a}}, 151,153$ & $Y=0.983 x+0.003$ & 0.998 & $50-2000$ & 10 \\
\hline ANA & 9.81 & $153^{\mathrm{a}}, 154,152$ & $Y=0.970 x+0.005$ & 0.997 & $50-2000$ & 10 \\
\hline FLU & 11.74 & $166^{\mathrm{a}}, 165,167$ & $Y=1.003 x-0.001$ & 0.999 & $50-2000$ & 10 \\
\hline PHE & 16.83 & $178^{\mathrm{a}}, 179,152$ & $Y=0.995 x+0.001$ & 0.999 & $50-2000$ & 15 \\
\hline ANT & 16.55 & $178^{\mathrm{a}}, 179,176$ & $Y=1.002 x-0.001$ & 0.999 & $50-2000$ & 15 \\
\hline FLT & 24.61 & $202^{\mathrm{a}}, 101,100$ & $Y=0.987 x+0.002$ & 0.999 & $50-2000$ & 15 \\
\hline PYR & 26.71 & $202^{\mathrm{a}}, 200,203$ & $Y=0.938 x+0.008$ & 0.995 & $50-2000$ & 15 \\
\hline $\mathrm{BaA}$ & 42.27 & $228^{a}, 226,229$ & $Y=0.944 x+0.008$ & 0.994 & $50-2000$ & 15 \\
\hline CHR & 42.50 & $228^{a}, 229,226$ & $Y=0.945 x+0.008$ & 0.994 & $50-2000$ & 15 \\
\hline $\mathrm{BbF}$ & 47.52 & $252^{\mathrm{a}}, 253,125$ & $Y=1.003 x-0.001$ & 0.999 & $50-2000$ & 20 \\
\hline BKF & 47.65 & $252^{\mathrm{a}}, 253,250$ & $Y=1.002 x-0.001$ & 0.999 & $50-2000$ & 20 \\
\hline $\mathrm{BaP}$ & 48.96 & $252^{\mathrm{a}}, 253,250$ & $Y=1.022 x-0.004$ & 0.999 & $50-2000$ & 20 \\
\hline IPY & 55.49 & $276^{a}, 277,138$ & $Y=0.985 x+0.003$ & 0.997 & $50-2000$ & 30 \\
\hline DBA & 55.81 & $278^{a}, 276,139$ & $Y=0.996 x-0.001$ & 0.999 & $50-2000$ & 30 \\
\hline BPE & 57.40 & $276^{\mathrm{a}}, 274,138$ & $Y=1.009 x-0.001$ & 0.999 & $50-2000$ & 30 \\
\hline
\end{tabular}

a Quantitation ion of each PAH for SIM.

phase separation was accomplished by centrifuging for $5 \mathrm{~min}$ at $15000 \mathrm{rpm}$ (high-speed refrigerated centrifuge, CR22N, Hitachi, Japan). The supernatant was transferred to another pre-cleaned $50-\mathrm{mL}$ centrifuge tube, and another $4.0 \mathrm{~mL}$ of GO solution was added for a second extraction as described above. The second supernatant was discarded and the GO aggregates were mixed to slurry with $1 \mathrm{~mL}$ hexane. The slurry was centrifuged for $1 \mathrm{~min}$ at $15000 \mathrm{rpm}$ and the supernatant was filtered through $0.22 \mu \mathrm{m}$ membrane (Tianjin Jinteng Experiment Equipment Ltd., Co., Tianjin, China) automatic sampling and analyzed by GC-MS.

\subsection{GC-MS Analysis}

The selected PAHs were analyzed on a Trace GC Ultra equipped with a DSQ 1 quadrupole MS system (Thermo, USA). Liquid samples of $1 \mu \mathrm{L}$ each were injected to the GC apparatus via a TriPlus RSH Autosampler by the headspace and liquid mode, respectively. The GC analyzer was equipped with a Thermo Scientific TR-5MS column (30 $\mathrm{m} \times 0.25 \mathrm{~mm} \times 0.25 \mu \mathrm{m}$ ). He (purity $\geq 99.999 \%$ ) was used as the carrier gas at the flow rate of $1.5 \mathrm{~mL} \mathrm{~min}^{-1}$. The oven temperature program was set as follows: $45^{\circ} \mathrm{C}$ for $0.8 \mathrm{~min}$, heated to $150^{\circ} \mathrm{C}$ at $25^{\circ} \mathrm{C} \mathrm{min}{ }^{-1}$, then to $200^{\circ} \mathrm{C}$ at $3^{\circ} \mathrm{C} \mathrm{min}{ }^{-1}$, and finally to $280^{\circ} \mathrm{C}$ at $8^{\circ} \mathrm{C} \mathrm{min}-1$ for $18 \mathrm{~min}$. The injection port, ion source, and interface temperatures were 250, 230, and $280^{\circ} \mathrm{C}$, respectively. The MS detector was operated in the electron ionization (EI) mode with an ionizing energy of $70 \mathrm{eV}$. The selective ion monitoring mode was adopted for the quantitative determination of the analytes, and the selected ion masses are listed in Table 1.

Ethical approval: The conducted research is not related to either human or animals use.

\section{Results and Discussion}

\subsection{Proposed Mechanism of Aggregation}

GO is regarded as a promising nanomaterial for the adsorption of pollutants because it features abundant O-containing functional groups, large surface areas, highly negative surface charge, and high adsorption capacity. The first study was designed to test whether PAHs could be adsorbed onto GO from water samples with high efficiency. Therefore, the river, lake, and sea water samples were treated for $10 \mathrm{~min}$ in the presence of GO to permit adsorption, and the contents of PAHs in pre- and post-treatment samples were determined with a standard SPE method [39]. The results (Fig 1) demonstrate that GO successfully adsorbed the PAHs. 
After adsorption, the GO solution must be aggregated for the separation of PAHs from the water sample. The GO sheets are highly negatively charged because of the edge carboxyl groups. Aqueous colloids and dispersions are stabilized via electrostatic repulsion; therefore, the dispersion and aggregation of GO depend on the degree of ionization of its carboxylic acid and phenolic hydroxyl groups. In this study, $\mathrm{NaCl}$ was chosen to neutralize the excessive negative charges and decrease the electrostatic repulsion to accomplish GO aggregation. The effect of $\mathrm{NaCl}$ on the zeta potential of GO was thus evaluated by an MPT-2 Zetasizer Nano (Malvern, England), with results

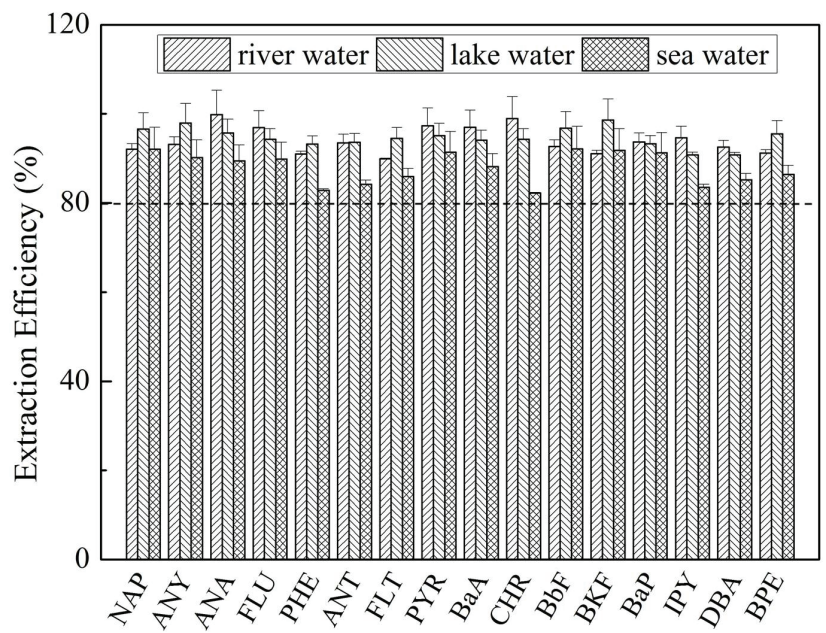

Figure 1: Extraction efficiency of PAHs with GO from river, lake and sea water. summarized in Figure 2. The change in zeta potential upon the introduction of $1000 \mu \mathrm{g} \cdot \mathrm{L}^{-1} \mathrm{PAHs}$ was negligible (Figure 2a), demonstrating that the GO solvent maintains good dispersion under high concentrations of PAHs. However, once $0.04 \mathrm{~g} \mathrm{~mL}^{-1}$ of $\mathrm{NaCl}$ was added to the $\mathrm{GO}$ solvent, the zeta potentials decreased sharply from -48.4 to $-25.0 \mathrm{mV}$. The effects of different $\mathrm{NaCl}$ masses on the zeta potential of $1 \mathrm{mg} \mathrm{mL}^{-1} \mathrm{GO}$ were studied as shown in Figure 2b. When the mass of $\mathrm{NaCl}$ was increased from 0.04 to $0.20 \mathrm{~g} \mathrm{~mL}^{-1}$, the zeta potential gradually increased from -25.0 to -4.4 $\mathrm{mV}$. A previous study found that instability in colloid dispersions, caused by insufficient mutual repulsion, appeared when the absolute zeta potential values were $<30 \mathrm{mV}[34,40]$. This proves that the introduction of $\mathrm{NaCl}$ can achieve GO aggregation and phase separation.

To further illuminate the morphologies of the GO sheets, transmission electron microscopy (TEM, HT7700, Hitachi, Japan) was used to observe changes in the images of $\mathrm{GO}$ after the addition of $\mathrm{NaCl}$, with results summarized in Figure 3. In Figure 3a, a large GO sheet with intrinsic wrinkles is observed. Figure $3 \mathrm{~b}$ shows the aggregated GO sheets, confirming that the neutralization of GO negative charges by $\mathrm{NaCl}$ induced $\mathrm{GO}$ aggregation in aqueous $\mathrm{GO}$ suspensions.

\subsection{Optimization of Extraction Conditions}

To optimize the adsorption conditions of PAHs by GO, DIW water spiked with the sixteen kinds of PAHs at
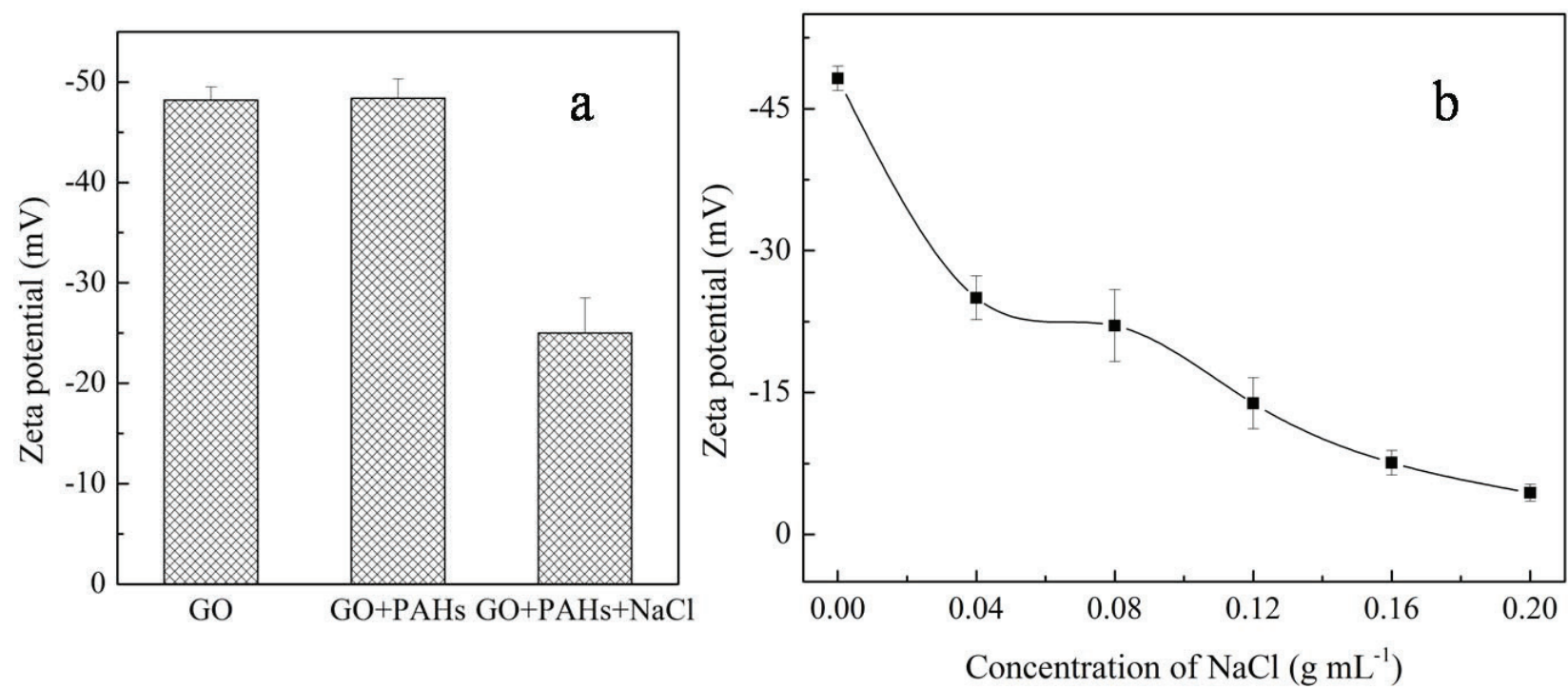

Figure 2: Zeta potential measurement of $\mathrm{GO}$ suspensions: (a) Zeta potential values after addition of PAHs $\left(1000 \mu \mathrm{g} \mathrm{mL}^{-1}\right)$ and $\mathrm{NaCl}(0.04 \mathrm{~g}$ $\left.\mathrm{mL}^{-1}\right)$ into $\mathrm{GO}$ suspensions ( $1 \mathrm{mg} \mathrm{mL}^{-1}$ ), and (b) Zeta potential of $\mathrm{GO}$ at $1 \mathrm{mg} \mathrm{mL}^{-1}$ as a function of $\mathrm{NaCl}$. 
a

$500 \mathrm{~nm}$ b

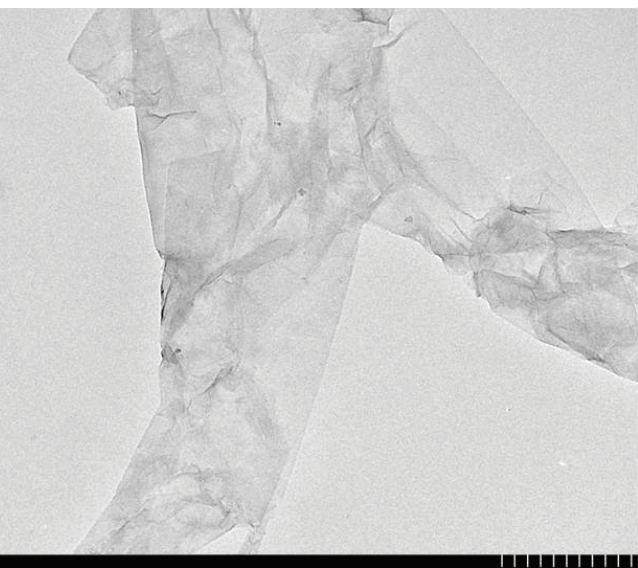

$500 \mathrm{~nm}$

Figure 3: TEM images of $\mathrm{GO}$ suspensions (a), and $\mathrm{GO}+\mathrm{PAHs}+\mathrm{NaCl}(\mathrm{b})$.

concentrations of $200 \mathrm{ng} \mathrm{L}^{-1}$ were used for sequential assessments. The extraction efficiency was evaluated by the recovery of the spiked PAHs.

As mentioned earlier, GO displays high affinity for the PAHs. However, the mass of the GO strongly affected the adsorption capacity for the analytes, which affected the extraction efficiency. In this work, the adsorption capacities of GO for PAHs were first investigated by adding $4.0 \mathrm{~mL}$ of $\mathrm{GO}$ dispersion solutions with different concentrations $\left(0.10-1.00 \mathrm{mg} \mathrm{mL}^{-1}\right)$ to a series of $40-\mathrm{mL}$ solutions containing $200 \mathrm{ng} \mathrm{L}^{-1}$ PAHs. The results are summarized in Figure 4a, which shows that the extraction efficiencies of all four tested PAH targets increased with increased mass of GO. A plateau for each analyte was obtained in the range of 2.0 to $4.0 \mathrm{mg}$ GO. Lower masses of GO resulted in the inefficient adsorption of the analytes because of the limited adsorption capacity of GO. Therefore, $4 \mathrm{~mL}$ of $\mathrm{GO}$ at $0.75 \mathrm{mg} \mathrm{mL}^{-1}$ was used for all subsequent extractions in this work.

The adsorption time of the PAHs onto GO is another critical parameter for the proposed method. Therefore, the effects of adsorption time were also studied, with results summarized in Figure 4b. All PAH compound recoveries increased with adsorption time in the range of 5 to $15 \mathrm{~min}$. A plateau occurred for times exceeding $15 \mathrm{~min}$, indicating that the GO and PAHs reach equilibrium in $15 \mathrm{~min}$. The adsorption time of $15 \mathrm{~min}$ was thus applied in subsequent experiments.

In the extraction, $\mathrm{NaCl}$ was chosen to neutralize the excessive negative charges and decrease the electrostatic repulsion to induce GO aggregation. Therefore, the effect of the concentration of $\mathrm{NaCl}$ on the extraction efficiency was investigated using $200 \mathrm{ng} \mathrm{L}^{-1}$ PAHs as the test samples. Results of these experiments are shown in
Figure 4c. A plateau of extraction efficiency for each $\mathrm{PAH}$ compound occurs in the range of $10-15 \mathrm{mg} \mathrm{mL}^{-1} \mathrm{NaCl}$ solution. The recoveries are decreased for both higher and lower concentrations of $\mathrm{NaCl}$. Lower $\mathrm{NaCl}$ concentrations resulted in inefficient GO aggregation and poor extraction efficiency of the analytes from the aqueous phase, while higher $\mathrm{NaCl}$ concentrations induced low analyte recovery from GO because of competition between $\mathrm{Na}^{+}$and the PAHs. Therefore, the $\mathrm{NaCl}$ concentration of $10 \mathrm{mg} \mathrm{mL}^{-1}$ was used for further experiments.

The GO aggregation could be observed immediately upon the addition of $\mathrm{NaCl}$. However, the deposition time was assessed to determine whether GO was completely deposited. Different deposition times were selected to evaluate the efficiency of GO aggregation, and the results were summarized in Figure $4 \mathrm{~d}$. The recoveries of all analytes reached $40-80 \%$ for the deposition time of $5 \mathrm{~min}$, and recoveries increased to $60-90 \%$ after $10 \mathrm{~min}$. For longer times, the recoveries plateau at approximately $100 \%$ for each analyte, indicating a deposition balance between $\mathrm{NaCl}$ and the $\mathrm{GO}$ solution. Therefore, we repeated the GO extraction and aggregation twice with $15 \mathrm{~min}$ allotted for each aggregation in subsequent studies to enhance the recoveries of the PAH compounds.

\subsection{Interference}

GO demonstrated high efficiency for PAH adsorption. However, some coexisting chemicals may affect the adsorption efficiencies of analytes if competitive adsorption occurs between the tested targets and potential interferential chemicals, such as inorganic ions and organic materials. Consequently, the effects of several 

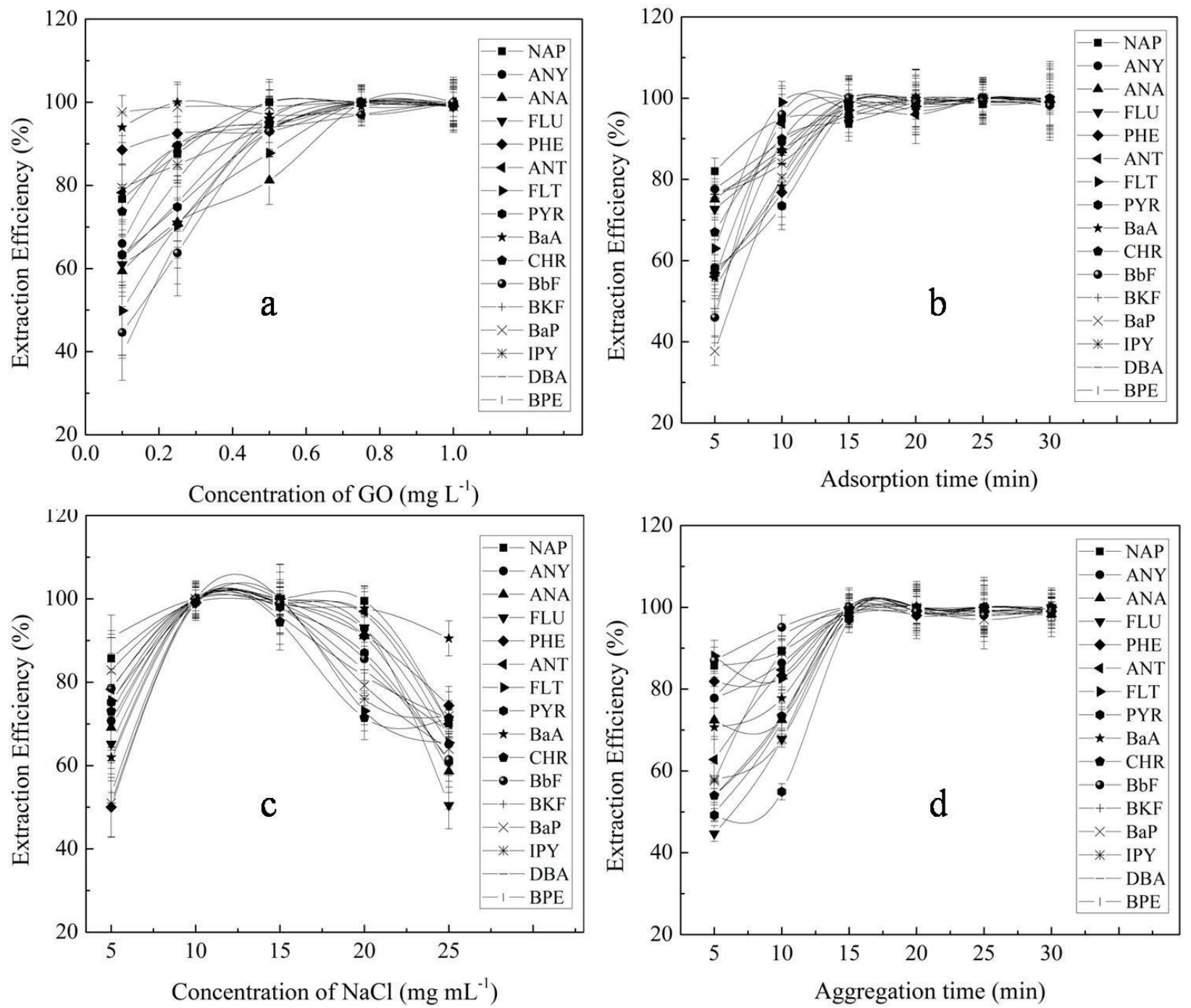

Figure 4: Optimization of the effects of influencing parameters on the extraction efficiency of PAHs. (a) Effect of concentration of GO. Adsorption time, $15 \mathrm{~min}$; concentration of $\mathrm{NaCl}, 10 \mathrm{mg} \mathrm{mL}^{-1}$; and aggregation time, $15 \mathrm{~min}$. (b) Effect of concentration of Adsorption time. Concentration of GO, $1.0 \mathrm{mg} \mathrm{L}^{-1}$; concentration of $\mathrm{NaCl}, 10 \mathrm{mg} \mathrm{mL}^{-1}$; and aggregation time, $15 \mathrm{~min}$. (c) Effect of concentration of $\mathrm{NaCl}$. Concentration of GO, $1.0 \mathrm{mg} \mathrm{L}^{-1}$; adsorption time, $15 \mathrm{~min}$; and aggregation time, $15 \mathrm{~min}$. (a) Effect of aggregation time. Concentration of GO, $1.0 \mathrm{mg} \mathrm{L}^{-1}$; adsorption time, $15 \mathrm{~min}$; and concentration of $\mathrm{NaCl}, 10 \mathrm{mg} \mathrm{mL}^{-1}$.

inorganic ions and organic materials were carefully studied. In these experiments, standard solutions of $200 \mathrm{ng} \mathrm{L}^{-1}$ of the PAHs were used, and 13 inorganic ions (namely $\mathrm{As}^{3+}, \mathrm{Ca}^{2+}, \mathrm{Cd}^{2+}, \mathrm{Co}^{2+}, \mathrm{Cr}^{3+}, \mathrm{Cu}^{2+}, \mathrm{Fe}^{3+}, \mathrm{Mg}^{2+}, \mathrm{Mn}^{2+}$, $\mathrm{Ni}^{2+}, \mathrm{Zn}^{2+}, \mathrm{Pb}^{2+}$, and $\mathrm{Se}^{2+}$ ) and 11 organic chemicals (namely chloroform, dichloromethane, carbon tetrachloride, dichlorvos, fenitrothion, malathion, mevinphos, fenthion, parathion, cypermethrin, and pirimicarb) at concentrations of $100 \mu \mathrm{g} \mathrm{mL}^{-1}$ were introduced. The results are summarized in Figure 5. With the tolerance limits defined as the largest concentrations of coexisting ions causing less than $15 \%$ signal variation, no significant interferences were observed.

\subsection{Analytical performance}

Analysis of PAHs by GC-MS was accomplished in the SIM mode based on the use of one target as quantification ion and two confirmation ions. PAHs were recognized according to their retention times, target and confirmation ions. The retention time, diagnostic ions and quantification ion for each analyte are presented in Table1. Representative selected ion chromatograms of non-spiked and spiked water samples are shown in Figure 6. The method showed no interfering background signal and therefore excellent selectivity for PAHs in the presence of other sample constituents. 

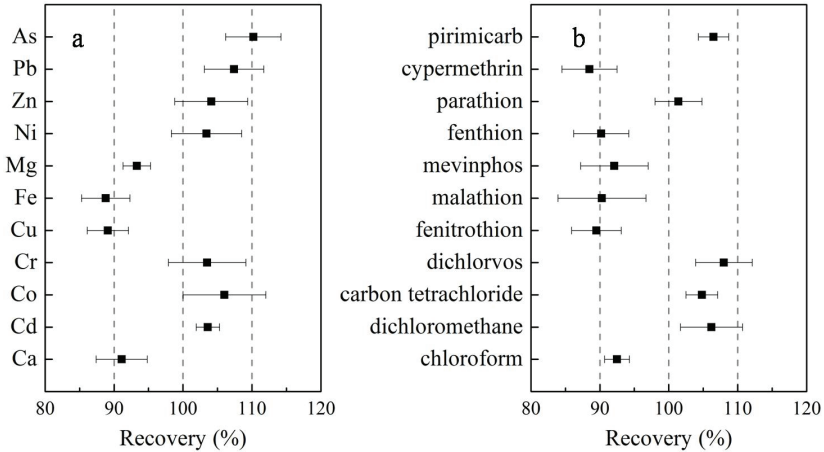

Figure 5: (a) Interferences owing to the coexistence of different inorganic ions at a concentration of $100 \mu \mathrm{g} \mathrm{mL}^{-1}$. (b) Interferences owing to the coexistence of different organic materials at a concentration of $100 \mu \mathrm{g} \mathrm{mL}^{-1}$.

The analytical performance of the PAHs obtained using GC-MS were evaluated under optimal experimental conditions. The linearity, regression, and linear ranges of the PAHs compounds are presented in Table 1. The linear coefficient $\left(\mathrm{R}^{2}\right)$ was better than 0.99 . The determined limits of detection (LODs), as defined as the lowest analyte concentration that yielded a signal of three times the signal-to-noise ratio $(\mathrm{S} / \mathrm{N})$, ranged from 10 to $30 \mathrm{ng}$ $\mathrm{L}^{-1}$. Considering that the Chinese Ministry of Health has established maximum residue limits (MRLs) of PAHs in drinking water at a value of $2 \mu \mathrm{g} \mathrm{L}^{-1}$ (GB 5749-2006, Chinese national standard), this method meets requirements for the determination of PAHs in water samples.

Theapplicability of the proposed method was first used to analyze 15 real samples from river, lake, and sea water to allow comparison with standard methods. The river and lake water samples were concentrated directly after filtering through a $0.22 \mu \mathrm{m}$ membrane filter. However, as mentioned earlier, GO aggregation occurred immediately upon GO addition because of the high salt content of sea water, which decreased the extraction efficiency. Therefore, with this method, sea water should be diluted before analysis, and no additional $\mathrm{NaCl}$ is needed to trigger GO aggregation in this case. However, the PAH contents in the water samples collected in Haikou were below the limits of quantitation (LOQs) of both the proposed and standard methods (data not shown). Therefore, river and sea water samples were chosen to further validate the accuracy of the proposed method via the evaluation of the recoveries of the spiked PAHs, because no certified $\mathrm{PAH}$ values in these samples are available. The results are summarized in Table 2. Satisfactory spike recoveries were measured in the ranges of $80-111 \%$ and $80-107 \%$ for real
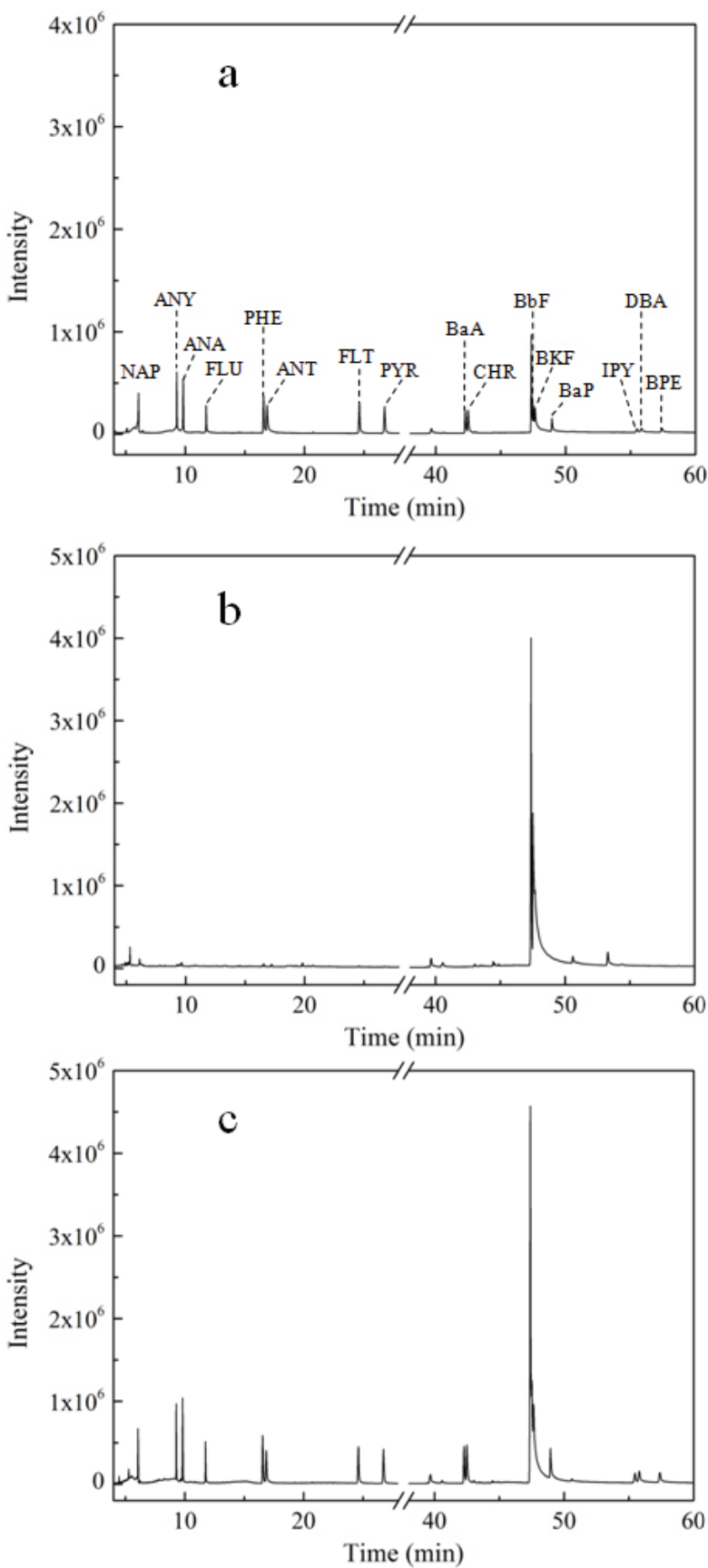

Figure 6: GC-MS chromatograms under SIM mode of PAHs in (a) PAHs standard solution, (b) blank water sample and (c) spiked water sample.

spiked water samples at 100 and $500 \mathrm{ng} \mathrm{L}^{-1}$, confirming the suitability of the proposed method for PAH analysis.

Comparisons of PAH analysis by the proposed and standard methods are summarized in Table 3. Extraction and separation by the aggregation of $\mathrm{GO}$ using $\mathrm{NaCl}$ as the electrolyte solution coupled to GC-MS detection is friendlier to the environment, simpler in operation, 
Table 2: Analytical performances of the developed method.

\begin{tabular}{|c|c|c|c|c|c|c|c|c|}
\hline \multirow[t]{2}{*}{ PAHs } & \multicolumn{4}{|c|}{ Added, $100 \mathrm{ng} \mathrm{L}^{-1}$} & \multicolumn{4}{|c|}{ Added, $500 \mathrm{ng} \mathrm{L}^{-1}$} \\
\hline & $\begin{array}{l}\text { Found } d^{a} \\
\left(n g L^{-1}\right)\end{array}$ & $\begin{array}{l}\text { Recovery } \\
\text { (\%) }\end{array}$ & $\begin{array}{l}\text { Found } \\
\left(\mathrm{ng} \mathrm{L}^{-1}\right)\end{array}$ & $\begin{array}{l}\text { Recovery } \\
\text { (\%) }\end{array}$ & $\begin{array}{l}\text { Found } d^{a} \\
\left(\text { ng L L-1) }^{-1}\right.\end{array}$ & $\begin{array}{l}\text { Recovery } \\
\text { (\%) }\end{array}$ & $\begin{array}{l}\text { Found } \\
\left(\mathrm{ng} \mathrm{L}^{-1}\right)\end{array}$ & $\begin{array}{l}\text { Recovery } \\
\text { (\%) }\end{array}$ \\
\hline NAP & $90.4 \pm 4.8$ & 90 & $106.1 \pm 7.9$ & 106 & $535.2 \pm 24.7$ & 107 & $451.0 \pm 34.8$ & 90 \\
\hline ANY & $103.2 \pm 7.0$ & 103 & $102.8 \pm 3.6$ & 103 & $440.8 \pm 37.3$ & 88 & $511.2 \pm 13.2$ & 102 \\
\hline ANA & $81.1 \pm 8.0$ & 81 & $103.3 \pm 6.0$ & 103 & $470.1 \pm 54.7$ & 94 & $466.8 \pm 19.0$ & 93 \\
\hline FLU & $103.1 \pm 6.9$ & 103 & $91.4 \pm 3.3$ & 91 & $448.3 \pm 40.3$ & 90 & $462.2 \pm 42.4$ & 92 \\
\hline PHE & $110.4 \pm 1.8$ & 110 & $89.5 \pm 5.7$ & 89 & $471.8 \pm 14.4$ & 94 & $453.8 \pm 25.2$ & 91 \\
\hline ANT & $110.3 \pm 8.2$ & 110 & $88.8 \pm 3.0$ & 89 & $441.7 \pm 19.4$ & 88 & $511.0 \pm 16.7$ & 102 \\
\hline FLT & $93.7 \pm 6.5$ & 94 & $94.2 \pm 4.3$ & 94 & $423.0 \pm 35.9$ & 85 & $462.2 \pm 19.3$ & 92 \\
\hline PYR & $81.7 \pm 5.9$ & 82 & $88.8 \pm 4.9$ & 89 & $438.3 \pm 16.9$ & 88 & $437.7 \pm 35.2$ & 88 \\
\hline $\mathrm{BaA}$ & $80.1 \pm 6.0$ & 80 & $96.7 \pm 7.3$ & 97 & $502.7 \pm 20.2$ & 101 & $509.0 \pm 39.9$ & 102 \\
\hline $\mathrm{CHR}$ & $84.8 \pm 4.6$ & 85 & $106.2 \pm 2.0$ & 106 & $438.6 \pm 15.6$ & 88 & $406.9 \pm 41.1$ & 81 \\
\hline $\mathrm{BbF}$ & $88.3 \pm 6.9$ & 88 & $109.0 \pm 2.0$ & 109 & $479.3 \pm 26.4$ & 96 & $457.8 \pm 22.1$ & 92 \\
\hline BKF & $110.3 \pm 2.0$ & 110 & $110.7 \pm 7.3$ & 111 & $495.8 \pm 37.0$ & 99 & $514.0 \pm 25.5$ & 103 \\
\hline $\mathrm{BaP}$ & $95.2 \pm 4.0$ & 95 & $89.2 \pm 5.5$ & 89 & $429.0 \pm 36.1$ & 86 & $443.2 \pm 23.4$ & 89 \\
\hline IPY & $87.9 \pm 3.4$ & 88 & $84.6 \pm 4.4$ & 85 & $470.2 \pm 35.6$ & 94 & $533.7 \pm 37.2$ & 107 \\
\hline DBA & $99.3 \pm 4.7$ & 99 & $100.3 \pm 8.3$ & 100 & $452.8 \pm 12.6$ & 91 & $474.4 \pm 25.9$ & 95 \\
\hline BPE & $86.7 \pm 6.5$ & 87 & $106.9 \pm 5.9$ & 107 & $489.8 \pm 26.9$ & 98 & $401.3 \pm 14.6$ & 80 \\
\hline
\end{tabular}

a Spiked river water samples, $n=3$; b Spiked seawater samples, $n=3$.

Table 3: Comparison of the features of the proposed method and the standard methods.

\begin{tabular}{|c|c|c|c|c|c|c|}
\hline & pretreated method & $\begin{array}{l}\text { determined } \\
\text { instrument }\end{array}$ & $\begin{array}{l}\text { organic reagents for } \\
\text { pretreatment }\end{array}$ & $\begin{array}{l}\text { organic reagents for } \\
\text { determination }\end{array}$ & $\begin{array}{l}\text { enrichment } \\
\text { coefficient }\end{array}$ & $\begin{array}{l}\text { LODs } \\
\left(\mathrm{ng} \mathrm{L}^{-1}\right)\end{array}$ \\
\hline $\begin{array}{l}\text { GB/T 26411- } \\
2010\end{array}$ & $\begin{array}{l}\text { solid phase } \\
\text { extraction }\end{array}$ & GC-MS & $\begin{array}{l}\text { methylene chloride, } 13 \mathrm{~mL} \text {; } \\
\text { methanol, } 1.5 \mathrm{~mL} \text {; } \\
\text { actone, } 1.5 \mathrm{~mL}\end{array}$ & hexane, $0.5 \mathrm{~mL}$ & 2000 & $1-2$ \\
\hline $\begin{array}{l}\text { EPA method } \\
610\end{array}$ & $\begin{array}{l}\text { Liquid-liquid } \\
\text { extraction }\end{array}$ & HPLC-UVD & methylene chloride, $150 \mathrm{~mL}$ & acetonitrile, $1 \mathrm{~mL}$ & 500 & $13-2300$ \\
\hline [15] & $\begin{array}{l}\text { multi-walled carbon } \\
\text { nanotubes SPE }\end{array}$ & GC-MS & $\begin{array}{l}25 \mathrm{~mL} \mathrm{n} \text {-hexane, } 10 \mathrm{~mL} \\
\text { methanol }\end{array}$ & hexane, $1 \mathrm{~mL}$ & 500 & $2.0-8.5$ \\
\hline [18] & $\begin{array}{l}\text { molecularly } \\
\text { imprinted SPE }\end{array}$ & GC-MS & $\begin{array}{l}2.0 \mathrm{~mL} \text { methanol/ } \mathrm{H}_{2} \mathrm{O}(1: 9 \\
\mathrm{v} / \mathrm{v}) ; 10 \mathrm{~mL} \text { DCM/acetic acid } \\
(9: 1, \mathrm{v} / \mathrm{v})\end{array}$ & $\begin{array}{l}0.5 \mathrm{~mL} \text { DCM/acetic acid } \\
(9: 1, \mathrm{v} / \mathrm{v})\end{array}$ & 60 & $5.2-12.6$ \\
\hline this method & $\begin{array}{l}\text { adsorption/ } \\
\text { aggregation }\end{array}$ & GC-MS & - & hexane, $1.0 \mathrm{~mL}$ & 50 & $10-30$ \\
\hline
\end{tabular}

and enhanced in both sample throughput and costeffectiveness.

\section{Conclusions}

In this work, GO was successfully applied for the preconcentration/separation of PAHs from water samples through aggregation by the addition of $\mathrm{NaCl}$. The method is free of organic reagents in the pretreatment procedure and uses only $1 \mathrm{~mL}$ hexane for sample introduction in GCMS. The proposed method is environmentally friendly and demonstrates great applicability for the green analysis of $\mathrm{PAH}$ contents in surface waters.

Acknowledgements: This project was funded in part by the National Science and Technology Major Project of the Ministry of Science and Technology of China (Grant No.16YFD0201203), the National Natural Science Foundation of China (No. 21467008), the International 
Cooperation Project of the Ministry of Agriculture (No. ZYLH2018010402), and the Central Public-interest Scientific Institution Basal Research Fund for Chinese Academy of Tropical Agricultural Sciences (No. 1630082018001, 1630082017005).

Conflict of interest: Authors state no conflict of interest.

\section{References}

[1] Rocha F.R.P., Nobrega J.A., Filho O.F., Flow analysis strategies to greener analytical chemistry. An overview, Green Chemistry, 2001, 3, 216-20.

[2] Keith L.H., Gron L.U., Young J.L., Green Analytical Methodologies, Chemical Reviews, 2007, 107, 2695-708.

[3] Ibrahim Ahmed S.A., Al-Farawati R., Hawas U., Shaban Y., Recent Microextraction Techniques for Determination and Chemical Speciation of Selenium, Open Chemistry, 2017, 15, 103-122.

[4] Keyte I.J., Harrison R.M., Lammel G., Chemical reactivity and long-range transport potential of polycyclic aromatic hydrocarbons - a review, Chemical Society Reviews, 2013, 42, 9333-91.

[5] El-Amin Bashir M., El-Maradny A., El-Sherbiny M., Mohammed Orif Rasiq K. T., Bio-concentration of Polycyclic Aromatic Hydrocarbons in the grey Mangrove (Avicennia marina) along eastern coast of the Red Sea, Open Chemistry, 2017, 15, 344351.

[6] Siemers A.-K., Mänz J.S., Palm W.-U., Ruck W.K., Development and application of a simultaneous SPE-method for polycyclic aromatic hydrocarbons (PAHs), alkylated PAHs, heterocyclic PAHs (NSO-HET) and phenols in aqueous samples from German Rivers and the North Sea, Chemosphere, 2015, 122, 105-14.

[7] Margoum C., Guillemain C., Yang X., Coquery M., Stir bar sorptive extraction coupled to liquid chromatography-tandem mass spectrometry for the determination of pesticides in water samples: Method validation and measurement uncertainty, Talanta, 2013, 116, 1-7.

[8] Fisichella M., Odoardi S., Strano-Rossi S., High-throughput dispersive liquid/liquid microextraction (DLLME) method for the rapid determination of drugs of abuse, benzodiazepines and other psychotropic medications in blood samples by liquid chromatography-tandem mass spectrometry (LC-MS/MS) and application to forensic cases, Microchemical Journal, 2015, 123, 33-41.

[9] Takáčová A., Smolinská M., Ryba J., Mackulak T., Jokrllová J., Hronec P., Čík G., Biodegradation of Benzo[a]Pyrene through the use of algae, Open Chemistry, 2014, 12, 1133-43.

[10] Smoker M., Tran K., Smith R.E., Determination of Polycyclic Aromatic Hydrocarbons (PAHs) in Shrimp, Journal of Agricultural and Food Chemistry, 2010, 58, 12101-4.

[11] Wen Y., Chen L., Li J., Liu D., Chen L., Recent advances in solid-phase sorbents for sample preparation prior to chromatographic analysis, TrAC Trends in Analytical Chemistry, 2014, 59, 26-41.
[12] Ma J., Yao Z., Hou L., Lu W., Yang Q., Li J., Chen L., Metal organic frameworks (MOFs) for magnetic solid-phase extraction of pyrazole/pyrrole pesticides in environmental water samples followed by HPLC-DAD determination, Talanta, 2016, 161, 686-92.

[13] Gu H.-X., Hu K., Li D.-W., Long Y.-T., SERS detection of polycyclic aromatic hydrocarbons using a bare gold nanoparticles coupled film system, Analyst, 2016, 141,4 359-65

[14] Hawthorne S.B., Jonker M.T.O., van der Heijden S.A., Grabanski C.B., Azzolina N. A., Miller D.J., Measuring Picogram per Liter Concentrations of Freely Dissolved Parent and Alkyl PAHs (PAH34), Using Passive Sampling with Polyoxymethylene, Analytical Chemistry, 2011,83,6754-61.

[15] Ma J., Xiao R., Li J., Yu J., Zhang Y., Chen L., Determination of 16 polycyclic aromatic hydrocarbons in environmental water samples by solid-phase extraction using multi-walled carbon nanotubes as adsorbent coupled with gas chromatographymass spectrometry, Journal of Chromatography A, 2010, 1217, 5462-9.

[16] Roy G., Vuillemin R., Guyomarch J., On-site determination of polynuclear aromatic hydrocarbons in seawater by stir bar sorptive extraction (SBSE) and thermal desorption GC-MS, Talanta, 2005, 66, 540-6.

[17] Jariwala D., Sangwan V.K., Lauhon L.J., Marks T.J., Hersam M.C., Carbon nanomaterials for electronics, optoelectronics, photovoltaics, and sensing, Chemical Society Reviews, 2013 , 42, 2824-60.

[18] Song X., Li J., Xu S., Ying R., Ma J., Liao C., Liu D., Yu J., Chen L., Determination of 16 polycyclic aromatic hydrocarbons in seawater using molecularly imprinted solid-phase extraction coupled with gas chromatography-mass spectrometry, Talanta, 2012, 99, 75-82.

[19] Wen Y., Niu Z., Ma Y., Ma J., Chen L., Graphene oxide-based microspheres for the dispersive solid-phase extraction of non-steroidal estrogens from water samples, Journal of Chromatography A, 2014, 1368, 18-25.

[20] Chen C., Zhou P., Wang N., Ma Y., San H., UV-Assisted Photochemical Synthesis of Reduced Graphene Oxide/ZnO Nanowires Composite for Photoresponse Enhancement in UV Photodetectors, Nanomaterials, 2018, 8, 26.

[21] Dreyer D.R., Park S., Bielawski C.W., Ruoff R.S., The chemistry of graphene oxide, Chemical Society Reviews, 2010, 39, 228-40.

[22] Si Y., Samulski E.T., Synthesis of water soluble graphene, Nano letters, 2008, 8, 1679-82.

[23] Li Y., Du Q., Liu T., Sun J., Wang Y., Wu S., Wang Z., Xia Y., Xia L., Methylene blue adsorption on graphene oxide/calcium alginate composites, Carbohydrate Polymers, 2013, 95, 501-7.

[24] Li Y., Du Q., Liu T., Peng X., Wang J., Sun J., Wang Y., Wu S., Wang Z., Xia Y., Comparative study of methylene blue dye adsorption onto activated carbon, graphene oxide, and carbon nanotubes, Chemical Engineering Research and Design, 2013, 91, 361-8.

[25] Ning F., Peng H., Li J., Chen L., Xiong H., Molecularly Imprinted Polymer on Magnetic Graphene Oxide for Fast and Selective Extraction of $17 \beta$-Estradiol, Journal of Agricultural and Food Chemistry, 2014, 62, 7436-43.

[26] Li L., Wang Z., Zhang S., Wang M., Directly-thiolated graphene based organic solvent-free cloud point extraction-like method 
for enrichment and speciation of mercury by HPLC-ICP-MS, Microchemical Journal, 2017, 132, 299-307.

[27] Mo J., Zhou L., Li X., Li Q., Wang L., Wang Z., On-line separation and pre-concentration on a mesoporous silica-grafted graphene oxide adsorbent coupled with solution cathode glow discharge-atomic emission spectrometry for the determination of lead, Microchemical Journal, 2017, 130, 353-9.

[28] Gao Y., Li Y., Zhang L., Huang H., Hu J., Shah S. M., Su X., Adsorption and removal of tetracycline antibiotics from aqueous solution by graphene oxide, Journal of Colloid and Interface Science, 2012, 368, 540-6.

[29] Wu M., Kempaiah R., Huang P.-J.J., Maheshwari V., Liu J., Adsorption and desorption of DNA on graphene oxide studied by fluorescently labeled oligonucleotides, Langmuir, 2011, 27, 2731-8.

[30] Xu J., Zheng J., Tian J., Zhu F., Zeng F., Su C., Ouyang G., New materials in solid-phase microextraction, TrAC Trends in Analytical Chemistry, 2013, 47, 68-83.

[31] Wang J., Chen Z., Chen B., Adsorption of Polycyclic Aromatic Hydrocarbons by Graphene and Graphene Oxide Nanosheets, Environmental Science \& Technology, 2014, 48, 4817-25.

[32] Zhao G., Li J., Ren X., Chen C., Wang X., Few-Layered Graphene Oxide Nanosheets As Superior Sorbents for Heavy Metal Ion Pollution Management, Environmental Science \& Technology, 2011, 45, 10454-62.

[33] Yang S.-T., Chang Y., Wang H., Liu G., Chen S., Wang Y., Liu Y., Cao A., Folding/aggregation of graphene oxide and its application in Cu2+ removal, Journal of Colloid and Interface Science, 2010, 351, $122-7$.
[34] Li D.,Müller M. B.,Gilje S.,Kaner R. B.,Wallace G. G., Processable aqueous dispersions of graphene nanosheets, Nature Nanotechnology, 2008,3,101.

[35] Chandra V., Kim K.S., Highly selective adsorption of $\mathrm{Hg} 2+$ by a polypyrrole-reduced graphene oxide composite, Chemical Communications, 2011, 47, 3942-4.

[36] Deng D., Jiang X., Yang L., Hou X., Zheng C., Organic Solvent-Free Cloud Point Extraction-like Methodology Using Aggregation of Graphene Oxide, Analytical Chemistry, 2014, 86, 758-65.

[37] Mateos R., Vera S., Díez-Pascual A.M., San Andrés M.P., Graphene solid phase extraction (SPE) of synthetic antioxidants in complex food matrices, Journal of Food Composition and Analysis, 2017, 62, 223-30.

[38] Xiao R., Zhang X., Zhang X., Niu J., Lu M., Liu X., Cai Z., Analysis of flavors and fragrances by HPLC with Fe304@GO magnetic nanocomposite as the adsorbent, Talanta, 2017, 166, 262-7.

[39] Determination of 16 polynuclear aromatic hydrocarbons in seawater by GC-MS. Beijing: Standards Press of China, 2010.

[40] White B., Banerjee S., O’Brien S., Turro N.J., Herman I.P., ZetaPotential Measurements of Surfactant-Wrapped Individual Single-Walled Carbon Nanotubes, Journal of Physical Chemistry C, 2007, 111, 13684-90. 